\title{
Smart City Technology: Ecological Sustainability
}

\author{
Anton Nazarov*, Natalya Tovmasyan, and Denis Kovtun \\ Ural State University of Economics, 620000 Yekaterinburg, Russia
}

\begin{abstract}
The Smart City concept includes a fairly wide range of characteristics of this new phenomenon for modern society. The main goal of creating smart cities is the comfortable living in them of people with a high level of well-being. The quality of living conditions for people in smart cities directly depends on how clean their natural environment is. The article examines the features of the development of the ecological vector of creating cities with maximum amenities for residents. Possible risks associated with negligence towards objects of animate and inanimate nature are listed, ways of high-quality environmental protection of cities of the future are outlined.
\end{abstract}

\section{Introduction}

The basic components of a set of measures aimed at improving the well-being of citizens through digitalization of key areas of the policy are:

- the use of innovative technologies that ensure the efficiency and environmental friendliness of the use of all systems of the city's life;

- simplification of the management of the internal processes of the city by creating a reliable and high-quality interconnection of communication, information technologies and the Internet of things;

- creation of a structure that allows efficient use of resources;

- effective use of the collective intelligence of the city due to the optimal interaction of several types of infrastructure - engineering, information and communication, business [2].

The Smart City assumes: a) smart way of life of smart people; b) smart economy; c) smart transport; d) smart management of all activity; e) smart environment.

\footnotetext{
* Corresponding author: nazarovad@usue.ru
} 


\section{Materials and Methods}

The smart lifestyle of smart people consists of competent consumption, a high culture of relationships between individuals, and a healthy lifestyle. In turn, smart people have all the necessary skills for using ICT, strive for self-enhancement, and actively participate in the life of society.

Smart economy means flexibility, productivity, innovative services and business models, effective cooperation.

Transport systems in a smart city should be integrated, all modes of transport should be environmentally friendly.

As part of smart management based on smart services, as many city residents as possible make decisions that satisfy the needs and demands of the entire population [7].

When creating a smart environment, it is necessary to pay attention to the issues of efficient energy consumption, the use of natural energy sources replenished by natural processes, the protection of living and inanimate natural objects, and resource conservation.

\section{Findings and Discussion}

The task of reducing the negative impact on the environmental safety of smart cities seems to be very important. Solution thereof requires:

- development of a strategy for effective waste management of enterprises and consumers for each city;

- mitigation of pollutant emissions into the atmosphere;

- enhancement of the quality of drinking water;

- measures to enhance water systems;

- harmonization of the balance of losses and reproduction of forest resources;

- deployment of digital technologies, while taking care of protecting the ecological balance of the biosphere;

- creation of all conditions for maintaining and restoring the health of citizens;

- integration of digitalization and industrial production on the condition of mandatory preservation of the ecosystem;

- training of the qualified personnel who are versed in both the use of digital technologies and environmental protection to develop infrastructure conducive to environmental safety.

It is important to develop anti-crisis economic models based on the multiplier aspect, combining environmental innovations with the sphere of production and economic activity. Apply in economic policy anti-crisis tools that have significant anti-crisis potential, stimulating the development of a "green" economic strategy.

The key idea of the environmental sustainability of smart cities is to increase production efficiency, human well-being in conditions of low environmental risks, prevent the degradation of living and non-living natural objects, efficient use of natural resources, return household and industrial waste to production operations to convert the initial raw material into finished products [6]. 


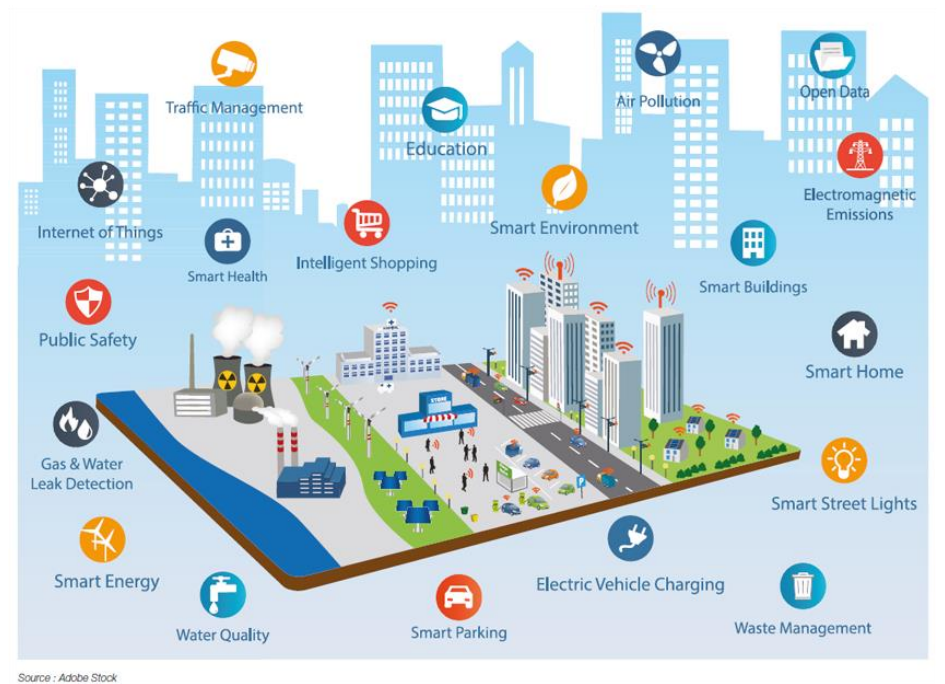

Fig. 1. Smart City: energy challenges facing sustainable cities.

The above requires: to develop state plans for the creation of smart cities, considering the individual characteristics of the landscape, the specifics of natural conditions that promote or hinder the development of social production; think over a system for the most efficient use of land resources. Build a city on several levels: 1) infrastructure for the use of various types of energy, primarily solar; 2) sustainable technologies for saving energy and resources; 3) access to repositories of information arrays; 4) smart residential buildings: optimal density, building height, landscaped and equipped public spaces; 5) health, safety, comfort, maximum satisfaction of social needs and needs of the population.

The level of environmental friendliness of construction technologies should be taken under special control: to develop individual plans for each building to ensure maximum comfort of work or living; exclude their construction process harmful to the environment types of work; to green the walls and roofs of buildings [5].

A fairly effective way to increase the level of environmental protection of smart cities seems to involve the administrations of citizens in cooperation on the development of a "green" economy: each individual should have the opportunity to make public their proposals for the use of environmental technologies, as well as take part in volunteer projects for landscaping areas, cleaning them from garbage.

Rejection of the "green" economic policy in the development of smart cities threatens a number of serious problems caused by often irreversible negative processes in the environment: depletion of natural capital, due to which the economic growth of the territory is ensured; the negative impact of polluted nature on the health of residents; an increase in the proportion of industries that pollute nature and aggressively exploit its resources; physical deterioration of equipment, which increases environmental risks; low indicators of environmental management efficiency; huge volumes of export of natural resources; lack of environmental balances in investment policy; the excessive volume of manufacturing sectors that pollute the surrounding world; the predominance in the economy of industries in which the specific costs of natural resources are very high per unit of the final product, or the specific values of pollution per unit of the final product are very high.

The negative ecological situation, the ecological crisis will impede the solution of the most important task of smart cities - the creation of the most comfortable living environment, will cause deterioration of human health, the growth of genetic diseases. It is already known that the economic costs of restoring the health of citizens, disturbed by air 
and water pollution, amount to about $5 \%$ of the GDP of a large European state. Therefore, environmental issues should come first in the planning and creation of smart cities [4].

\section{Conclusions}

A high level of reliability of the power supply of a smart city may be provided by water resources, e.g., the energy of tides, rivers, and technically accessible geothermal sources. In this regard, the sun, wind, thermal energy of the earth, as well as organic waste from agriculture, waste from the woodworking industry, solid waste from smart cities themselves, and even from municipal wastewater have significant potential in this regard. That is, alternative energy is becoming one of the most important factors in the environmental protection of smart cities.

It is necessary to develop the "green" sector of smart cities on the basis of the following principles.

Sophisticated pricing: valuation of natural resources in monetary terms; elimination of ineffective subsidies; imposing taxes on environmentally damaging actions.

Specific product procurement system: encouraging the production of environmentally friendly goods; use of production methods oriented towards sustainable development.

Tax modernization: lower taxes on labor with a gradual increase in taxes on environmental pollution.

Increasing public investment in smart transport, in renewable resources from which useful energy is collected, in the creation of buildings with low energy consumption, in the restoration, maintenance, growth of natural production resources [1].

Preventing the expansion of traditional energy sources through digital energy management, partial power supply of urban lighting and urban electric transport systems using solar energy, the use of special solar panels for the cladding of high-rise buildings, the development of innovative technologies for collecting and storing energy.

Systematic support of research and development for the creation and implementation of environmentally friendly technologies in the infrastructure of smart cities.

Harmonization of social, economic and environmental strategies for the formation and development of smart cities.

An introduction to the programs of higher and secondary economic education of the environmental component for smart cities. Development of special programs for teaching life activities that do not harm the environment in smart cities for preschool educational institutions.

"Greening" of production technologies by tightening state enforcement measures for the excess in production of natural capital costs in relation to the volume of the product produced [3]. Improvement of legal mechanisms that implement the strict implementation of current laws on environmental protection.

Compliance with the above principles will contribute to the environmental sustainability of smart cities, improving the life quality and the well-being of the population.

\section{References}

1. M.V. Babenko, S.I. Bick, A.I. Postnova, Green Economy: Definitions and Concepts. Moscow: World Wildlife Fund (WWF), 36 (2018)

2. A.Yu. Inyutsyn, Practice of Municipal Governance 2, 46 (2017)

3. S.N. Bobylev, A.A. Goryachev, V.I. Nemova, Public Administration. Electronic Bulletin, 64 (2017)

4. V. Kalner, Ecology and Industry of Russia 22(1), 62 (2018) 
5. I.A. Kruglova, V.A. Plotnikov, Proceedings of the International Banking Institute 1 (23), 18 (2018)

6. A.V. Lomovtseva, Solving the ecological problems of urbanized areas: the transition to "smart cities", Ecology and nature management: trends, models, forecasts, applied aspects: materials Nat. scientific-practical conf./RSAU them. P.A.Kostycheva. Ryazan, 79 (2020)

7. A.S. Plohotnyuk, Skif. Student Science Issues 3, 43 (2016)

8. Z. Allam, Z.A. Dhunny, Cities 89, 80 (2019)

9. M. Artmann, M. Kohler, G. Meinel, J. Gan, I. Ioja, Ecological Indicators 96, 10 (2019)

10. S.I. Drozhzhin, A.V. Shiyan, S.A. Mityagin, Smart city implementation and aspects: The case of st. petersburg, 14 (2019)

11. F. Gianni, S. Mora, M. Divitini, Future Generation Computer Systems 95, 867 (2019)

12. H. Huang, M. Zhang, K. Yu, Y. Gao, J. Liu, Computer Communications 154, 380 (2020)

13. P. Kremer, A. Haase, D. Haase, Sustainable Cities and Society, 51 (2019)

14. H. R. Marston, L. Shore, P. J. White, International Journal of Environmental Research and Public Health 17(21), 1 (2020)

15. C. Martin, J. Evans, A. Karvonen, K. Paskaleva, D. Yang, T. Linjordet, Sustainable Cities and Society 45, 640 (2019)

16. S. A. Nitoslawski, N.J. Galle, C. K. van den Bosc, J. W. N. Steenberg, Sustainable Cities and Society, 51 (2019)

17. Y. Patel, N. Doshi, Procedia Computer Science 155, 692 (2019)

18. E. Popov, S. Kortov, K. Semyachkov, Intellectual capital of smart cities as objects for institutional modeling. Paper presented at the Proceedings of the European Conference on Intellectual Capital, 210 (2019).

19. T. V. Ramachandra, J.M. Sellers, H.A. Bharath, S. Vinay, Spatial Information Research 27(1), 37 (2019)

20. I. Turgel, L. Bozhko, E. lyanova, A. Khabdullin, Environmental and Climate Technologies 23(2), 148 (2019)

21. T. M. Vinod Kumar, Smart environment for smart cities (2020) 